\title{
New malignancies after squamous cell carcinoma and melanomas: a population-based study from Norway
}

Trude E Robsahm ${ }^{1 *}$, Margaret R Karagas ${ }^{2}$, Judy R Rees ${ }^{2}$ and Astri Syse ${ }^{3}$

\begin{abstract}
Background: Skin cancer survivors experience an increased risk for subsequent malignancies but the associated risk factors are poorly understood. This study examined the risk of a new primary cancer following an initial skin cancer and assessed risk factors associated with second primary cancers.

Methods: All invasive cutaneous malignant melanomas (CMM, N =28 069) and squamous cell carcinomas (SCC, $N=24$ 620) diagnosed in Norway during 1955-2008 were included. Rates of new primary cancers in skin cancer survivors were compared to rates of primary malignancies in the general population using standardized incidence ratios (SIR). Discrete-time logistic regression models were applied to individual-level data to estimate cancer risk among those with and without a prior skin cancer, accounting for residential region, education, income, parenthood, marital status and parental cancer status, using a 20\% random sample of the entire Norwegian population as reference. Further analyses of the skin cancer cohort were undertaken to determine risk factors related to subsequent cancers.

Results: During follow-up, 9608 new primary cancers occurred after an initial skin cancer. SIR analyses showed 50\% and $90 \%$ increased risks for any cancer after CMM and SCC, respectively $(p<0.01)$. The logistic regression model suggested even stronger increase after SCC (130\%). The highest risk was seen for subsequent skin cancers, but several non-skin cancers were also diagnosed in excess: oral, lung, colon, breast, prostate, thyroid, leukemia, lymphoma and central nervous system. Factors that were associated with increased risk of subsequent cancers include male sex, older age, lower residential latitude, being married and low education and income. Parental cancer did not increase the risk of a subsequent cancer after SCC, but was a significant predictor among younger CMM survivors.

Conclusions: Our results provide information on shared environmental and genetic risk factors for first and later cancers and may help to identify individuals at high risk for subsequent cancers, which will be important as skin cancer incidence continues to rise.
\end{abstract}

Keywords: Malignant Melanoma, Squamous Cell Carcinoma, Second cancer, Population-based, Sociodemographic factors, Family

\section{Background}

Cutaneous squamous cell carcinoma (SCC) and malignant melanoma (CMM) are among the most prevalent [1] and rapidly increasing malignancies in white populations worldwide [2]. In Norway, the incidence of these cancers has increased sevenfold during the last fifty years. In 2010, SCC and CMM represented more than $10 \%$ of all new cancer cases in Norway [3]. The major

\footnotetext{
* Correspondence: trude.eid.robsahm@kreftregisteret.no

'Cancer Registry of Norway, PB 5313 Majorstuen, N-0304 Oslo, Norway

Full list of author information is available at the end of the article
}

environmental risk factor for all skin cancers is ultraviolet radiation (UVR) from sunlight; consequently, there is a distinct north-south gradient in skin cancer risk [4]. The type of UVR exposure (e.g. intermittent versus accumulated) appears to differ for SCC and CMM [5]. In addition, individual characteristics such as skin type, eye and hair color, nevi and immune suppression are important predictors of individual susceptibility to skin cancer [6,7]. High socioeconomic status is also associated with CMM [8].

\section{Biomed Central}

(c) 2014 Robsahm et al.; licensee BioMed Central Ltd. This is an Open Access article distributed under the terms of the Creative Commons Attribution License (http://creativecommons.org/licenses/by/2.0), which permits unrestricted use, distribution, and reproduction in any medium, provided the original work is properly credited. 
SCC is a highly curable disease, and the most recent five-year relative survival rates in Norway are $89 \%$ and 93\% for men and women respectively [3]. Although CMM carries a higher mortality rate, the 5-year survival rate is still high $(77 \%$ and $89 \%$ for men and women, respectively) [3], due to early diagnosis and successful treatment. During the last fifteen years, several studies have suggested that a history of skin cancer increases the risk for a new primary cancer, both of the skin and other sites [9-30]. Many of these studies were based on cancer registry data, with high quality case ascertainment but lacking data on individual risk factors that might explain this. Other studies have benefitted from individual exposure data collected using questionnaires, but these tended to be smaller and have less rigorous confirmation of skin and subsequent cancers. A reduced risk of new malignancies after skin cancer has also been reported for some cancer sites [31-37], which some argue is due to the potentially protective effect of high levels of vitamin D that result from UVR exposure [38].

From the Nordic countries, Sweden, Finland and Denmark have reported their risks of second cancers after skin cancer [12-14,18,28,29], whereas Norway has not previously reported on these risks. Therefore, we used the Norwegian Cancer Registry data to describe the risk of a new primary cancer following SCC or CMM, and to further assess whether sociodemographic factors or cancer family history were associated with risk of subsequent cancers after skin cancer. Identifying those at greatest risk for subsequent cancers may benefit future public health initiatives by targeting interventions appropriately in the prevention and/or early detection of subsequent malignancies.

\section{Methods}

\section{Study population}

Our study cohort included all persons with a histologically verified invasive cutaneous malignant melanoma $(\mathrm{N}=28069)$ or squamous cell carcinoma $(\mathrm{N}=24620)$ diagnosed as a first primary cancer in the period 19552008 (Table 1). The Cancer Registry of Norway has registered all cancer diagnoses nationwide from 1953 onwards (not including basal cell carcinoma of skin). Mandatory reporting from multiple independent sources ensures the collection of complete and high quality data [39]. Available information includes date and type of primary skin cancer diagnosis, stage, and anatomical location (head/ neck, trunk, arm, leg/foot or other sites) as well as similar data on subsequent cancers. To distinguish new primary cancers from recurrences, the Cancer Registry uses histological information and medical record review; if the histology reports are similar, at least four months must have passed since the initial cancer diagnosis for a later case to be defined as a new primary cancer and clinical records must be consistent with a new primary according to the cancer registry standard [39].

The Norwegian Population Register, the Norwegian Education Register and the Norwegian Directorate of Taxes provided information for the cases as well as the general population on individual level characteristics such as date of birth, emigration and death, residential region, attained educational level (1960, 1970, and yearly from 1980 onwards), income (annual from 1966 onwards), parity, and marital status. The data were linked through unique personal identification numbers assigned to every individual residing in Norway from 1960 onwards. Permission to match the data was provided by the National Data Inspectorate in Norway after ethical review of this study by the Norwegian Board of Medical Ethics.

For our study, we obtained individual-level data on all residents during the period 1955-2008 ( $\mathrm{N}=5.3$ million). We used all skin cancer cases and a $20 \%$ random sample of the entire population for comparison ( $\mathrm{N}=1.1$ million). Follow-up for skin cancer cases began on the date of diagnosis. For the general population, follow-up began either at age 20 or age in 1955 if greater than 20 at that time. Age and calendar period were included as time-varying covariates, 20-39, 40-59 and $\geq 60$ years and 1955-64, 1965-74, 1975-84, 1985-94, 1995-2004 and 2005 and above, respectively. As the majority of Norwegians have completed their education by age 25 and having children by age 35 for the time period under consideration, we used educational level and parental status at end of follow-up in our models. For residential region, marital status and income, we modeled status at the start of follow-up. The average follow-up time was 10.1 years for skin cancer survivors, and 30.6 years for the general population.

We examined the associations between an initial skin cancer and new primary cancers of the skin as well as mouth/pharynx, lung, breast, prostate, thyroid, leukemia and lymphomas, which are the sites with the most evidence of an association in earlier studies [10-12,14-16,19, 21,23,25-30]. Exploratory analyses were also undertaken to examine the risk of second cancer at other common sites.

We examined the risk of second cancers by age at diagnosis because young age at onset of the initial cancer may indicate a genetic predisposition. We examined residence by latitude (South, Mid and North, as previously described [40]) because the association between skin cancer and subsequent malignancies is hypothesized to be strongest further from the equator [21]. To account for detection bias attributable to increased attention to cancer symptoms after a skin cancer diagnosis, we also examined the short- and long-term risks of subsequent cancer after diagnosis of a primary skin cancer. 
Table 1 Descriptive features of the cohort of persons with a first primary cutaneous malignant melanoma (CMM) or squamous cell carcinoma (SCC) at time of the primary skin cancer diagnosis

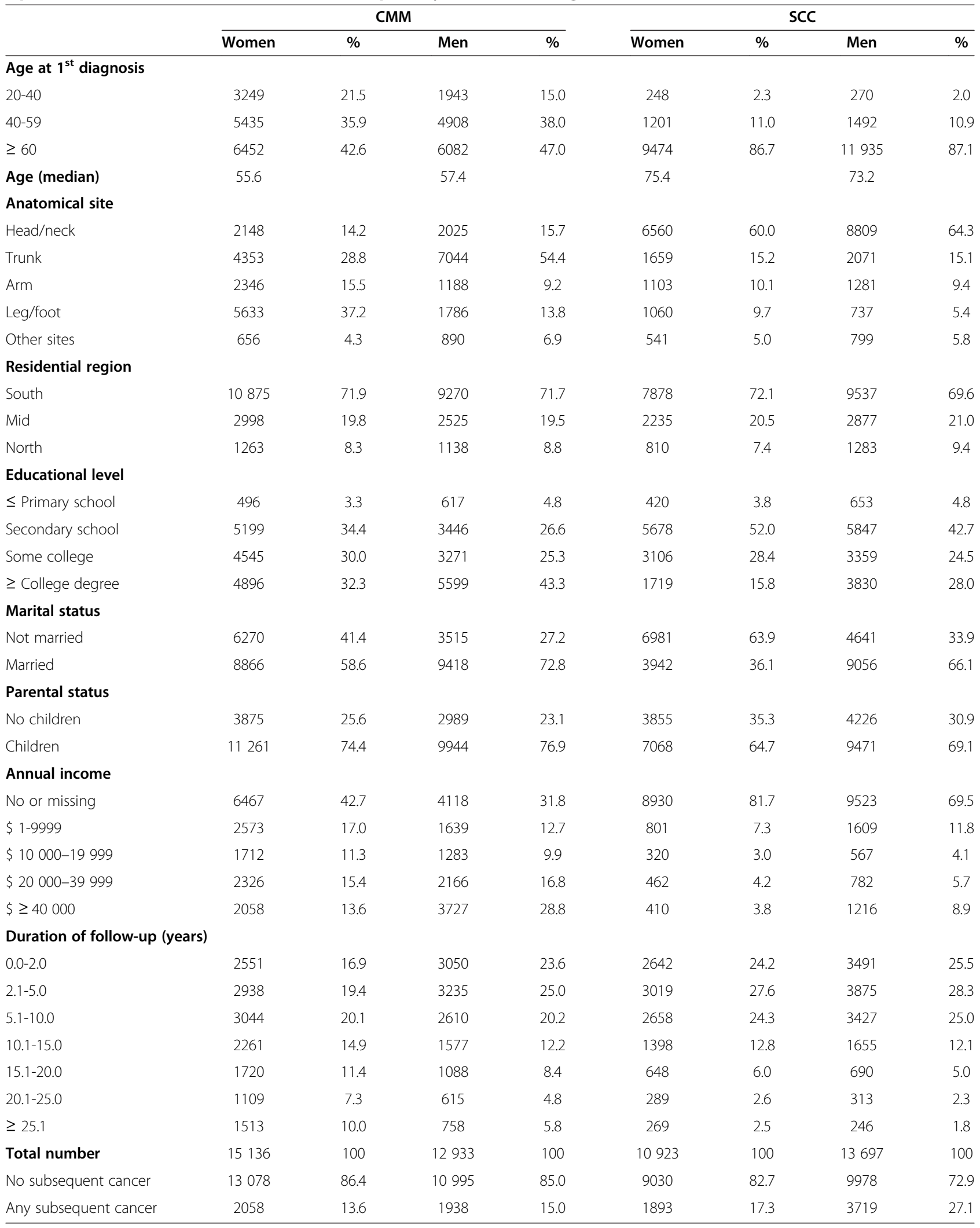


We obtained information on parental cancer diagnoses for the skin cancer survivors who had identified parents (i.e. were alive in 1960). Overall, we were able to link $60 \%$ of the skin cancer survivors with their mother and $55 \%$ with their father. In general, the linkage rate decreased with increasing age at diagnosis, and we thus performed analyses stratified by year of birth (all, birth year > 1930 and birth year > 1950).

\section{Statistical analyses}

Three types of analyses were conducted. First, we used standardized incidence ratios (SIR) to compare rates of subsequent malignancies in skin cancer survivors with rates of first primary cancer in subgroups of the general population of comparable age, sex and calendar time. The person-years at risk and the observed number of cancer cases were counted by sex within 5-year age groups $(20-24, \ldots, 80-84,85+)$, and 5-year calendar periods $(1955-59, \ldots, 2000-04)$, except for the last period which ran from 2005-08. The expected number of cancer cases was calculated by multiplying the number of person-years in each age group and calendar period in the skin cancer cohort by the corresponding cancer rates in the general Norwegian population. The 95\% confidence interval (CI) for the SIR was based on the assumption that the observed number of cases was Poisson-distributed and the expected number was non-stochastic. The analyses were performed using Stata 12 [41].

Second, a discrete-time logistic regression model was used to assess the importance of individual-level risk factors for the risk of a new primary cancer after skin cancer versus a first primary malignancy. Series of twelve-month observations were created for each individual. Individuals were followed from start of follow-up to a first primary malignancy (in a $20 \%$ random selection of the general population) or a subsequent malignancy (in skin cancer survivors). Individuals were followed to 2008, unless death, emigration or a malignancy occurred before this time. The follow-up time was categorized as 0-2 years, 3-5 years, 6-10 years, 11-15 years, 1620 years, $21-25$ years or more than 25 years. Categorizations of the covariates are shown in Table 2. Interaction terms between a primary skin cancer diagnosis and the various sociodemographic features were included to assess possible effect modification. Based on these results, stratified analyses were undertaken on variables for which effect modification appeared to be present.

Third, internal analyses were undertaken to examine whether cancer-related and sociodemographic factors influence the risk of subsequent malignancies within the cohort of skin cancer survivors. The analyses explored the possible impact of the anatomic site of the primary skin cancer and history of parental cancer. All the discrete-time models were run using the PROC
LOGISTIC procedure in SAS 9.2 [42]. Time to subsequent malignancies in men and women was explored using Kaplan-Meier plots, separately for CMM (Figure 1A) and SCC (Figure 1B) survivors, using Stata 12 [41]. The statistical significance level was set at $5 \%$.

\section{Results}

Overall, 3996 and 5612 subsequent cancers occurred, respectively, among CMM and SCC survivors during follow-up. The characteristics of individuals diagnosed with skin cancer are displayed in Table 1. CMM patients were diagnosed at an earlier age, were better educated, had higher incomes, were more frequently married and had children than SCC patients.

\section{Standard incidence ratios (SIR)}

We found $50 \%$ and $90 \%$ increases in the risks of subsequent cancer after an initial CMM and a SCC diagnosis, respectively (Tables 3,4). The strongest risks were observed for subsequent skin cancers, and in particular for skin cancers of the same histology as the index cancer. Increased risks were also observed for several non-skin cancers (thyroid, breast, prostate, leukemia and lymphomas) after both types of skin cancer. After CMM, a 30\% increase in risk of central nervous system (CNS) tumors was observed and in men we observed a decreased risk of lung cancer. After SCC, more than a threefold and a sixfold risk increase was observed for mouth/pharynx and salivary gland tumors respectively, as well as a nearly $50 \%$ risk increase for lung cancer. Further, the risks of pancreatic and colon cancer were significantly elevated in both sexes, but in women we found a decreased risk of cancers of urinary organs.

\section{Logistic regression models}

As several cancer forms are associated with socioeconomic status, site-specific analyses controlling for sociodemographic and -economic risk factors were conducted. Results were fairly similar to those observed in the SIR analyses (Table 5), e.g., for the risk of breast cancer after either CMM or SCC. However, the model resulted in higher risk estimates for leukemia, lymphoma and colon cancer after CMM or SCC and for cancers of urinary organs after SCC. For prostate cancer there was a lower estimate after CMM but higher after SCC.

Table 2 shows estimates from a fully saturated discrete-time logistic regression model, comparing the risk of a first cancer in the general population with that of a second cancer in skin cancer survivors. Compared to the general population, the cancer risk was approximately 50\% and 130\% higher after an initial CMM and SCC, respectively. An increased cancer risk was associated with male sex, older age, lower residential latitude, recent calendar time, primary education, low income and being married. 
Table 2 Odds ratios (OR) and 95\% confidence intervals (CI) from a fully saturated discrete-time logistic regression model, comparing the risk of a first cancer in the general population with that of a second cancer in skin cancer survivors

\begin{tabular}{|c|c|c|c|c|}
\hline & \multicolumn{2}{|c|}{ CMM } & \multicolumn{2}{|c|}{ SCC } \\
\hline & Events/Pyr ${ }^{1}$ & OR $(95 \% \mathrm{Cl})$ & Events/Pyr & OR $(95 \% \mathrm{Cl})$ \\
\hline \multicolumn{5}{|l|}{ Primary skin cancer } \\
\hline No & 143 978/31.0 mill & 1.00 ref & 144 179/31.0 mill & 1.00 ref \\
\hline Yes & $3662 / 288823$ & $1.53(1.48,1.59)$ & $5612 / 175641$ & $2.30(2.22,2.37)$ \\
\hline \multicolumn{5}{|l|}{ Sex } \\
\hline Female & 72 768/15.8 mill & 1.00 ref & 72 319/15.7 mill & 1.00 ref \\
\hline Male & 75 206/15.4 mill & $1.28(1.26,1.29)$ & 77 472/15.4 mill & $1.31(1.29,1.32)$ \\
\hline \multicolumn{5}{|l|}{$\mathrm{Age}^{2}$} \\
\hline 20-40 years & 6447/12.0 mill & 1.00 ref & 6509/12.0 mill & 1.00 ref \\
\hline $40-59$ years & 30 795/10.6 mill & $5.37(5.22,5.52)$ & 30 241/10.5 mill & $5.28(5.14,5.43)$ \\
\hline$\geq 60$ years & 110 732/8.6 mill & $20.58(20.04,21.14)$ & 113 041/8.6 mill & $20.34(19.80,20.9)$ \\
\hline \multicolumn{5}{|l|}{ Residential region ${ }^{3}$} \\
\hline North & 21 277/6.0 mill & 1.00 ref & 21 323/6.0 mill & 1.00 ref \\
\hline Mid & 34 586/7.2 mill & $1.30(1.27,1.32)$ & 34878/7.2 mill & $1.30(1.28,1.32)$ \\
\hline South & 92 111/18.0 mill & $1.33(1.31,1.35)$ & 93 590/17.9 mill & $1.35(1.33,1.37)$ \\
\hline \multicolumn{5}{|l|}{ Calendar period $^{2}$} \\
\hline$<1965$ & $8477 / 4.3$ mill & 1.00 ref & 8354/4.3 mill & 1.00 ref \\
\hline 1965-1974 & 20 484/5.4 mill & $2.54(2.47,2.61)$ & 20 867/5.4 mill & $2.62(2.56,2.6)$ \\
\hline 1975-1984 & 27 276/5.9 mill & $3.63(3.54,3.73)$ & 27 573/5.9 mill & $3.73(3.63,3.83)$ \\
\hline 1985-1994 & 33 071/6.3 mill & $4.28(4.17,4.40)$ & 33 817/6.3 mill & $4.45(4.34,4.57)$ \\
\hline 1995-2004 & 40 142/6.6 mill & $5.33(5.19,5.47)$ & 40 241/6.6 mill & $5.41(5.27,5.56)$ \\
\hline$\geq 2005$ & 18 524/2.7 mill & $5.99(5.82,6.17)$ & 18 939/2.6 mill & $6.22(6.04,6.40)$ \\
\hline \multicolumn{5}{|l|}{ Educational level $^{4}$} \\
\hline$\leq$ Primary school & 15 926/1.9 mill & 1.00 ref & 16 141/1.9 mill & 1.00 ref \\
\hline Secondary school & 67 042/11.8 mill & $0.32(0.31,0.33)$ & 67 915/11.8 mill & $0.32(0.31,0.33)$ \\
\hline Some college & 35 646/7.0 mill & $0.30(0.29,0.31)$ & 36 079/7.0 mill & $0.30(0.29,0.30)$ \\
\hline$\geq$ College degree & 29 360/10.5 mill & $0.30(0.29,0.31)$ & 29 656/10.4 mill & $0.30(0.30,0.31)$ \\
\hline \multicolumn{5}{|l|}{ Marital status ${ }^{3}$} \\
\hline Not married & 47 085/15.7 mill & 1.00 ref & 47 881/15.7 mill & 1.00 ref \\
\hline Married & $100889 / 15.5$ mill & $1.25(1.24,1.27)$ & 101 910/15.4 mill & $1.27(1.25,1.28)$ \\
\hline \multicolumn{5}{|l|}{ Parental status ${ }^{4}$} \\
\hline No children & 138 424/28.9 mill & 1.00 ref & 139 451/28.9 mill & $1.00 \mathrm{ref}$ \\
\hline Children & 9550/2.3 mill & $0.95(0.93,0.97)$ & $10340 / 2.2$ mill & $0.96(0.94,0.98)$ \\
\hline \multicolumn{5}{|l|}{ Income (annual) ${ }^{3}$} \\
\hline$\$ 0^{5}$ & 60 395/9.1 mill & 1.00 ref & 62 871/9.1 mill & 1.00 ref \\
\hline$\$ 80-9999$ & 40 528/10.7 mill & $0.92(0.90,0.93)$ & 40 556/10.7 mill & $0.91(0.90,0.92)$ \\
\hline \$ $10000-19999$ & 34 425/8.7 mill & $0.80(0.79,0.82)$ & 34 394/8.7 mill & $0.80(0.78,0.80)$ \\
\hline$\$ 20000-39999$ & 11 582/2.6 mill & $0.78(0.77,0.80)$ & 11 140/2.5 mill & $0.76(0.74,0.78)$ \\
\hline$\$ \geq 40000$ & $1044 / 153034$ & $0.82(0.77,0.87)$ & $830 / 122013$ & $0.78(0.73,0.84)$ \\
\hline
\end{tabular}

${ }^{1}$ Number of events (new cancers) per person-year during follow-up. ${ }^{2}$ Time-varying covariates (yearly). ${ }^{3}$ At start of follow-up. ${ }^{4}$ At end of follow-up. ${ }^{5}$ Includes also those with missing income data.

In the comparison between CMM survivors and the general population, interactions were observed for educational attainment, attained age and calendar period
( $\mathrm{p}_{\text {interaction }}<0.01$ ). In stratified analyses, the risk of a subsequent cancer was higher for CMM survivors with an education at college or university level (Odds ratio (OR) 1.65, 


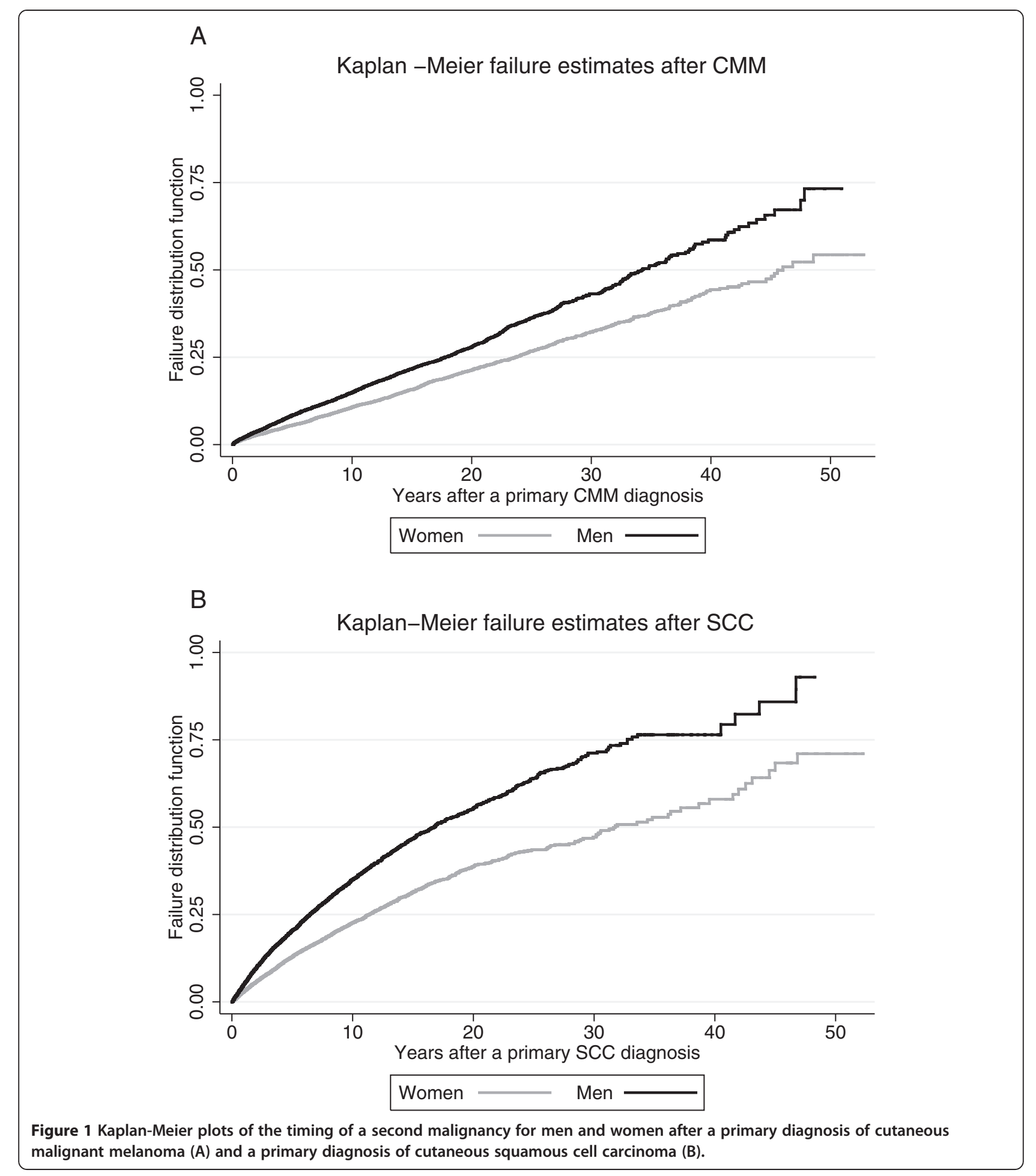

CI 1.57-1.74) than for those with a lower education (OR 1.34, CI 1.26-1.42). Similarly, a CMM diagnosis before the age of 60 significantly increased the risk of a subsequent cancer (OR 2.59, CI 2.41-2.79) compared to those older than 60 years (OR 1.43, CI 1.37-1.50). The interaction term between calendar year as a linear variable and CMM diagnosis suggested an increase in risk with more recent calendar time. However, splitting the sample at year 1990 did not identify appreciable differences ( $\leq 1990$ : OR 1.57 , CI 1.50-1.64 vs. > 1990: OR 1.64, CI 1.52-1.77).

For SCC survivors in comparison to the general population, interactions were found for parental status, 
Table 3 Standard incidence ratios (SIR) with $95 \%$ confidence intervals (CI) for a second malignancy by cancer site in men and women with a history of cutaneous malignant melanoma (CMM), adjusted for age and calendar period

\begin{tabular}{|c|c|c|c|c|c|}
\hline \multirow[b]{2}{*}{ ICD-10 } & \multirow[b]{2}{*}{ Cancer site $^{2}$} & \multicolumn{2}{|c|}{ Women $\left(\mathrm{N}=15184^{1}\right)$} & \multicolumn{2}{|c|}{ Men $\left(\mathrm{N}=12972^{1}\right)$} \\
\hline & & $0^{3}$ & SIR $(95 \% \mathrm{CI})$ & $0^{3}$ & SIR $(95 \% \mathrm{Cl})$ \\
\hline C00-14 & Mouth, pharynx & 14 & $0.77(0.46,1.30)$ & 33 & $1.11(0.79,1.56)$ \\
\hline C18 & Colon & 163 & $1.02(0.88,1.19)$ & 134 & $1.16(0.98,1.37)$ \\
\hline C19-21 & Rectum & 57 & $0.87(0.67,1.13)$ & 62 & $0.93(0.72,1.19)$ \\
\hline C25 & Pancreas & 46 & $1.00(0.76,1.33)$ & 39 & $1.06(0.77,1.45)$ \\
\hline C33,34,38 & Lung & 109 & $1.12(0.93,1.35)$ & 119 & $0.72(0.60,0.87)$ \\
\hline C50 & Breast & 377 & $1.24(1.12,1.37)$ & - & - \\
\hline C50-58 & Female organs & 588 & $1.18(1.09,1.28)$ & - & - \\
\hline C61 & Prostate & - & - & 445 & $1.26(1.15,1.38)$ \\
\hline C64-68 & Urinary organs & 68 & $0.93(0.73,1.18)$ & 139 & $0.99(0.84,1.17)$ \\
\hline C70-72 & $\mathrm{CNS}^{4}$ & 70 & $1.39(1.09,1.75)$ & 41 & $1.31(0.98,1.78)$ \\
\hline C73 & Thyroid & 19 & $1.27(0.81,1.99)$ & 13 & $2.78(1.61,4.80)$ \\
\hline C81-85 & Lymphoma & 56 & $1.29(0.99,1.68)$ & 60 & $1.56(1.20,1.99)$ \\
\hline C91-95 & Leukemia & 72 & $1.28(1.01,1.60)$ & 64 & $1.22(0.87,1.43)$ \\
\hline$C 00-96^{5}$ & Other sites & 169 & $1.15(0.99,1.34)$ & 176 & $1.07(0.92,1.24)$ \\
\hline C43 & CMM & 438 & $7.59(6.91,8.33)$ & 411 & $9.44(8.57,10.4)$ \\
\hline C44 & SCC & 197 & $3.12(2.71,3.59)$ & 204 & $3.11(2.71,3.56)$ \\
\hline C00-96 & All sites & 2066 & $1.52(1.46,1.59)$ & 1943 & $1.49(1.43,1.60)$ \\
\hline Coo- $96^{6}$ & All, exc. skin & 1431 & $1.16(1.11,1.23)$ & 1328 & $1.12(1.06,1.18)$ \\
\hline $\mathrm{C} 00-96^{7}$ & All, exc. CMM & 1628 & $1.26(1.20,1.32)$ & 1532 & $1.25(1.19,1.31)$ \\
\hline
\end{tabular}

${ }^{1}$ The number of cancer cases in the SIR-analyses differs slightly from that used in the logistic regression analyses as the data were extracted on different dates from the Cancer Registry of Norway. ${ }^{2}$ The cancer sites are not mutually exclusive. ${ }^{3}$ Observed number of cases. ${ }^{4}$ Central nervous system tumors. ${ }^{5}$ Includes ICD-10 codes C15-17, C22-24, C26, C30-32, C37, C39-41, C45-49, C60, C62-63, C69, C74-76, C80, C88, C90. ${ }^{6}$ All sites except C43 and C44. ${ }^{7}$ All sites except C43.

educational attainment, attained age and calendar period ( $\mathrm{p}_{\text {interaction }}<0.01$ ). Risk for a subsequent cancer was higher for SCC survivors with at least one child (OR 2.64, CI 2.48-2.80) compared to those without children (OR 2.26, CI 2.15-2.37). Further, a higher risk of subsequent cancer was observed for SCC survivors with an education at college or university level (OR 2.49, CI 2.38-2.62) compared to those with a lower education (OR 1.97, CI 1.89-2.06). SCC diagnosis before the age of 60 was associated with a higher risk of subsequent cancer (OR 5.54, CI 4.88-6.29) compared to those older than 60 years (OR 2.07, CI 2.00-2.15). Risk of subsequent cancer was also higher after 1990 (OR 2.52, CI 2.42-2.62) than prior to this (OR 2.29, CI 2.15-2.42).

\section{Risk of subsequent cancer among skin cancer survivors}

The results for the internal comparisons were quite similar for the two subgroups of skin cancer survivors and they confirmed the findings from the external analyses (Table 6). No clear difference in the overall risk of subsequent cancer was found across the anatomical sites of the primary skin cancer, after CMM or SCC (data not shown). This was true for all cancer sites, skin included.

\section{Parental cancer}

The risk for a new primary cancer after an initial CMM was not associated with a history of cancer in their mother (OR 1.05, CI 0.90-1.23), father (OR 0.95, CI 0.81-1.11) or either parent (OR 1.00, CI 0.88-1.13), for individuals born after 1930. When we restricted the analyses to those with complete parental linkage (individuals born after 1950), the respective estimates were elevated; risks of cancer after CMM in individuals with a history of cancer in their mother, father or either parent were 1.39 (CI 1.09-1.78), 1.38 (CI 1.09-1.76) and 1.52 (CI 1.21-1.92) respectively. For SCC survivors, the estimates associated with parental cancer were not significantly elevated in the overall or restricted analyses (data not shown).

\section{Time since first primary cancer}

The risk of subsequent cancer after an initial skin cancer increased with time and the risk excess was greater for men than for women (Figures $1 \mathrm{~A}$ and $\mathrm{B}$ ). Whereas the increase appeared almost linear for CMM survivors, it rose in a non-linear manner for SCC survivors. 
Table 4 Standard incidence ratios (SIR) and 95\% confidence intervals (CI) for a second malignancy by cancer site in men and women with a history of cutaneous squamous cell carcinoma (SCC), adjusted for age and calendar period

\begin{tabular}{|c|c|c|c|c|c|}
\hline \multirow[b]{2}{*}{ ICD-10 } & \multirow[b]{2}{*}{ Cancer site $^{2}$} & \multicolumn{2}{|c|}{ Women $\left(\mathrm{N}=10965^{1}\right)$} & \multicolumn{2}{|c|}{ Men $\left(N=13748^{1}\right)$} \\
\hline & & $0^{3}$ & SIR $(95 \% \mathrm{CI})$ & $\mathrm{O}^{3}$ & SIR $(95 \% \mathrm{CI})$ \\
\hline $\mathrm{COO}-14^{4}$ & Mouth, pharynx & 38 & $3.03(2.20,4.16)$ & 114 & $3.23(2.69,3.87)$ \\
\hline C07-08 & Salivary glands & 11 & $6.69(3.71,12.1)$ & 17 & $6.19(3.85,9.95)$ \\
\hline C18 & Colon & 176 & $1.25(1.08,1.45)$ & 197 & $1.09(0.95,1.25)$ \\
\hline C19-21 & Rectum & 45 & $0.86(0.64,1.14)$ & 96 & $0.98(0.80,1.20)$ \\
\hline C25 & Pancreas & 45 & $1.03(0.77,1.38)$ & 82 & $1.39(1.12,1.73)$ \\
\hline $\mathrm{C} 33,34,38$ & Lung & 82 & $1.46(1.17,1.81)$ & 303 & $1.49(1.32,1.66)$ \\
\hline C50 & Breast & 204 & $1.15(1.00,1.32)$ & - & - \\
\hline C50-58 & Female organs & 320 & $1.11(0.99,1.24)$ & - & - \\
\hline C61 & Prostate & - & - & 650 & $1.14(1.06,1.23)$ \\
\hline C64-68 & Urinary organs & 42 & $0.69(0.51,0.94)$ & 222 & $1.08(0.94,1.23)$ \\
\hline C70-72 & $\mathrm{CNS}^{5}$ & 17 & $0.65(0.40,1.04)$ & 32 & $1.10(0.78,1.56)$ \\
\hline C73 & Thyroid & 12 & $7.30(4.15,12.8)$ & 3 & $0.60(0.19,1.85)$ \\
\hline C81-85 & Lymphoma & 64 & $2.14(1.67,2.74)$ & 113 & $2.41(2.00,2.90)$ \\
\hline C91-95 & Leukemia & 65 & $1.33(1.04,1.69)$ & 150 & $1.70(1.45,1.99)$ \\
\hline $\mathrm{COO}-96^{6}$ & Other sites & 183 & $1.13(0.98,1.31)$ & 371 & $1.37(1.23,1.51)$ \\
\hline C43 & CMM & 95 & $3.09(2.52,3.78)$ & 122 & $2.76(2.31,3.29)$ \\
\hline C44 & SCC & 715 & $9.88(9.18,10,6)$ & 1249 & $10.1(9.51,10.6)$ \\
\hline C00-96 & All sites & 1898 & $1.89(1.81,1.98)$ & 3725 & $1.91(1.84,1.96)$ \\
\hline $\mathrm{COO}-96^{7}$ & All, exc. skin & 1088 & $1.22(1.15,1.30)$ & 2354 & $1.33(1.28,1.39)$ \\
\hline $\mathrm{COO}-96^{8}$ & All, exc. SCC & 1183 & $1.23(1.16,1.30)$ & 2476 & $1.31(1.25,1.36)$ \\
\hline
\end{tabular}

${ }^{1}$ The number of cancer cases in the SIR-analyses differs slightly from that used in the logistic regression analyses as the data were extracted on different dates from the Cancer Registry of Norway. ${ }^{2}$ The cancer sites are not mutually exclusive. ${ }^{3}$ Observed number of cases. ${ }^{4}$ Includes ICD-10 codes C00-06 and C09-14. ${ }^{5} \mathrm{Central}$ nervous system tumors. ${ }^{6}$ Includes ICD-10 codes C15-17, C22-24, C26, C30-32, C37, C39-41, C45-49, C60, C62-63, C69, C74-76, C80, C88, C90. ${ }^{7}$ All sites except C43 and C44. ${ }^{8}$ All sites except C44.

\section{Discussion}

The risk of a new primary cancer was higher after an initial skin cancer compared to the risk of a first primary cancer in the general Norwegian population, using multiple approaches. The highest risk was found for a subsequent skin cancer, but several non-skin cancers were also diagnosed in excess including oral, colon, lung, breast, prostate, urinary organs, CNS, thyroid, leukemia and lymphomas. Many of the associations we observed have been reported previously, but we were able to account for a number of sociodemographic factors, and show that the risks remained elevated. Among skin cancer survivors an elevated risk of subsequent cancer was associated with male sex, older age, lower residential latitude, primary education only, low income and being married and the risk increased over the study period. Having children was associated with a slightly decreased cancer risk. Having a parent with a history of cancer increased the risk for a new primary cancer after CMM if diagnosed before age 60 .

Individual risk of skin cancer is determined by UVR and host susceptibility [43]. These are the likely explanations for the increased risk of skin and perhaps lip cancer after a CMM or SCC diagnosis, but medical surveillance after the diagnosis may also be important. However, the reasons why individuals with a history of skin cancer have a higher risk of non-cutaneous malignancies, than those without a skin cancer history, are less obvious.

As in previous reports [9,10,14-16,18,19,21-23,25-30,36], we also observed that a history of skin cancer increased the risk of leukemia and lymphoma. Although the mechanism for such an association is not fully understood, several mechanisms have been suggested. First, UVR impairs the immune system, both locally in the skin and systemically [44-46]. Moreover, immunodeficiency as a result of the disease itself $[27,47,48]$, genetic factors [44] or previous treatment with radiation or chemotherapy $[49,50]$, are all potentially shared risk factors.

We found a history of SCC to be related to an increased risk of lung and mouth/pharynx cancers which is consistent with several previous observations $[9,12,16$, 19-21,23,24,26-30,51]. Although UVR has been suggested to play a role also for these cancer types, similar relationships were not observed after CMM. The most 
Table 5 Odds ratios (OR) and $95 \%$ confidence intervals (CI) of subsequent cancer by cancer site for cohorts with a primary cutaneous malignant melanoma (CMM) or cutaneous squamous cell carcinoma (SCC) relative to that of the general population, adjusted for covariates shown in Table $\mathbf{2}^{1}$

\begin{tabular}{|c|c|c|c|c|c|}
\hline \multirow[b]{2}{*}{ ICD-10 } & \multirow[b]{2}{*}{ Cancer site $^{2}$} & \multicolumn{2}{|c|}{ CMM } & \multicolumn{2}{|c|}{ SCC } \\
\hline & & Events $^{3}$ & OR $(95 \% \mathrm{Cl})$ & Events & OR (95\% Cl) \\
\hline$\overline{C 00-14^{4}}$ & Oral cavity & 2768 & $0.96(0.68,1.34)$ & 2876 & $2.70(2.19,3.34)$ \\
\hline C07-08 & Salivary glands & 257 & $0.62(0.14,2.74)$ & 291 & $8.89(5.29,14.93)$ \\
\hline C18 & Colon & 13281 & $1.28(1.12,1.46)$ & 13190 & $1.62(1.43,1.82)$ \\
\hline C19-21 & Rectum & 6696 & $1.15(0.93,1.42)$ & 6768 & $1.10(0.91,1.33)$ \\
\hline C25 & Pancreas & 4551 & $1.14(0.89,1.45)$ & 4590 & $1.56(1.27,1.91)$ \\
\hline C33,34,38 & Lung & 12347 & $0.72(0.62,0.84)$ & 12613 & $1.23(1.09,1.36)$ \\
\hline C50 & Breast & 17275 & $1.21(1.07,1.36)$ & 16956 & $1.16(1.01,1.34)$ \\
\hline C50-58 & Female organs & 29775 & $1.11(1.02,1.22)$ & 29349 & $1.08(0.96,1.21)$ \\
\hline C61 & Prostate & 17398 & $1.17(1.02,1.34)$ & 17797 & $1.28(1.14,1.43)$ \\
\hline C64-68 & Urinary organs & 10607 & $1.00(0.85,1.18)$ & 10787 & $1.18(1.03,1.37)$ \\
\hline C70-72 & $\mathrm{CNS}^{5}$ & 4348 & $1.73(1.39,2.15)$ & 4149 & $1.07(0.79,1.44)$ \\
\hline C73 & Thyroid & 1437 & $1.75(1.19,2.56)$ & 1435 & $1.27(0.75,2.16)$ \\
\hline C81-85 & Lymphoma & 4672 & $1.42(1.14,1.76)$ & 4678 & $2.78(2.33,3.32)$ \\
\hline C91-95 & Leukemia & 6096 & $1.63(1.33,1.99)$ & 6162 & $2.15(1.83,2.53)$ \\
\hline $\mathrm{COO}-96^{6}$ & Other sites & 21969 & $1.27(1.13,1.43)$ & 22373 & $1.67(1.51,1.84)$ \\
\hline C43 & CMM & 6363 & $7.99(7.19,8.88)$ & 5827 & $3.45(2.94,4.05)$ \\
\hline C44 & SCC & 5382 & $3.31(2.86,3.82)$ & 6906 & $14.4(13.2,15.7)$ \\
\hline C00-96 & All sites & 147974 & $1.53(1.48,1.59)$ & 149791 & $2.30(2.22,2.37)$ \\
\hline $\mathrm{COO}-96^{7}$ & All, exc. skin & 136229 & $1.16(1.11,1.21)$ & 137058 & $1.51(1.46,1.57)$ \\
\hline
\end{tabular}

${ }^{1}$ The number of cancer cases in the SIR-analyses differs slightly from that used in the logistic regression analyses as the data were extracted on different dates from the Cancer Registry of Norway. The number of cases are nevertheless quite similar (CMM: SIR 28156 vs 28069 , events 4009 vs 3996 and SCC: SIR 24713 vs 24620 , event 5623 vs 5612). ${ }^{2}$ The cancer sites are mutually exclusive. ${ }^{3}$ Observed number of events in a $20 \%$ general population sample and the cohort of skin cancer survivors. ${ }^{4}$ Includes ICD-10 codes C00-06 and C09-14. ${ }^{5}$ Central nervous system tumors. ${ }^{6}$ Includes ICD-10 codes 150-152, 155, 156, 158-161, 164, 178, 179, 192, and 195-199. ${ }^{7}$ All sites except C43 and C44.

reasonable explanation for the increased risk of lung and oral cancer in SCC survivors may be related to tobacco use, which also has been suggested as a risk factor for SCC [29,51]. Moreover, a primary SCC was associated with an increased risk of cancer in urinary organs that also might be related to tobacco. While we have no information on tobacco use, prior studies that were able to control for tobacco use still observed an increased risk of lung $[20,30]$, oral and kidney cancers [30]. Thus, it is possible that the relationship observed between SCC and cancers of mouth/pharynx, lung, and urinary organs lies elsewhere.

The risk of thyroid cancer was significantly increased, both after an initial CMM (both sexes) and SCC (women only), also consistent with previous findings [11,21, 25-27,31]. Common risk factors such as genetic or environmental exposure have been suggested to explain this association [25]. A cancer diagnosis may also increase future health vigilance, which may result in increased detection of new malignancies. Physical examination for CMM includes lymph node palpation in the thyroid area and we cannot exclude the possibility of such surveillance bias. Unfortunately, our numbers were too small to enable a detailed analysis of the development of thyroid cancer with time from a primary skin cancer diagnosis.

With respect to the elevated risk of CNS tumors, we cannot exclude the possibility that the second primary cancer, reported by the clinicians as a CNS tumor, could in some patients be a metastasis from the primary CMM. As CMM but not SCC is likely to spread to the brain, this may explain why no such association was observed between SCC and risk of CNS tumors.

In line with previous studies [10,15,21,25,27,33,34,52], an initial skin cancer diagnosis was found to be associated with an increased risk of colon, breast and prostate cancer. For breast cancer, the relationship was most pronounced after a primary diagnosis of CMM. Shared hormonal mechanisms for CMM and breast cancer have been proposed, although the epidemiological evidence of the role of hormones in melanoma etiology is inconsistent [52]. All these three cancer forms, as well as skin cancer, are associated with high socioeconomic status, and shared risk factors linked to socioeconomic status may account for the positive relationship, including frequent screening activity $[25,34]$. For CMM survivors this 
Table 6 Odd ratios (OR) and 95\% confidence intervals (CI) from a fully saturated discrete-time logistic regression model examining the risk for a subsequent cancer diagnosis within the cohorts with a primary cutaneous malignant melanoma (CMM) or squamous cell carcinoma (SCC)

\begin{tabular}{|c|c|c|c|c|}
\hline & \multicolumn{2}{|c|}{ CMM } & \multicolumn{2}{|c|}{ SCC } \\
\hline & Events/Pyr ${ }^{1}$ & OR $(95 \% \mathrm{Cl})$ & Events/Pyr & OR $(95 \% \mathrm{Cl})$ \\
\hline \multicolumn{5}{|l|}{ Sex } \\
\hline Female & 2058/173 679 & 1.00 ref & 1893/81 108 & $1.00 \mathrm{ref}$ \\
\hline Male & 1938/115 144 & $1.51(1.41,1.63)$ & $3719 / 94533$ & $1.90(1.79,2.01)$ \\
\hline \multicolumn{5}{|l|}{$\mathrm{Age}^{2}$} \\
\hline$<40$ years & $80 / 31862$ & 1.00 ref & 19/3020 & $1.00 \mathrm{ref}$ \\
\hline 40-59 years & $807 / 106669$ & $2.89(2.29,3.65)$ & $222 / / 17362$ & $2.28(1.42,3.66)$ \\
\hline$\geq 60$ years & $3109 / 147183$ & $6.67(5.31,8.39)$ & $5371 / 155259$ & $4.62(2.93,7.29)$ \\
\hline \multicolumn{5}{|l|}{ Residential region ${ }^{3}$} \\
\hline North & $275 / 23927$ & 1.00 ref & $419 / 15325$ & $1.00 \mathrm{ref}$ \\
\hline Mid & $703 / 54955$ & $1.09(0.95,1.26)$ & $1124 / 37786$ & $1.09(0.98,1.23)$ \\
\hline South & $3018 / 209941$ & $1.20(1.06,1.36)$ & $4069 / 122530$ & $1.20(1.08,1.33)$ \\
\hline \multicolumn{5}{|l|}{ Calendar period $^{2}$} \\
\hline$<1965$ & $6 / 2959$ & $1.00 \mathrm{ref}$ & $35 / 4411$ & 1.00 ref \\
\hline 1965-1974 & $71 / 13448$ & $3.01(1.30,6.98)$ & $168 / 10542$ & $2.51(1.73,3.64)$ \\
\hline 1975-1984 & 276/34 380 & $4.92(2.15,11.24)$ & $438 / 22580$ & $3.61(2.50,5.20)$ \\
\hline 1985-1994 & $913 / 69763$ & $7.80(3.43,17.34)$ & $1281 / 40225$ & $6.46(4.52,9.24)$ \\
\hline 1995-2004 & $1707 / 112983$ & $8.88(3.91,20.17)$ & $2364 / 64765$ & $7.76(5.44,11.1)$ \\
\hline$\geq 2004$ & $1023 / 55290$ & $10.52(4.63,23.9)$ & $1326 / 33118$ & $8.73(6.10,12.5)$ \\
\hline \multicolumn{5}{|l|}{ Educational level $^{4}$} \\
\hline$\leq$ Primary & $63 / 5193$ & 1.00 ref & $178 / 6203$ & 1.00 ref \\
\hline Secondary & $1285 / 85407$ & $0.80(0.61,1.04)$ & $2514 / 82333$ & $0.60(0.50,0.71)$ \\
\hline Some college & $1293 / 85733$ & $0.79(0.60,1.05)$ & $1577 / 46489$ & $0.60(0.50,0.72)$ \\
\hline$\geq$ College degree & $1355 / 112490$ & $0.80(0.61,1.05)$ & $1343 / 40616$ & $0.61(0.51,0.74)$ \\
\hline \multicolumn{5}{|l|}{ Marital status ${ }^{3}$} \\
\hline Not married & 1089/84 671 & $1.00 \mathrm{ref}$ & $2161 / 72265$ & 1.00 ref \\
\hline Married & 2907/204 152 & $1.02(0.94,1.10)$ & $3451 / 103376$ & $1.01(0.95,1.08)$ \\
\hline \multicolumn{5}{|l|}{ Parental status ${ }^{4}$} \\
\hline No children & $881 / 68530$ & 1.00 ref & $1692 / 56884$ & $1.00 \mathrm{ref}$ \\
\hline Children & $3115 / 220293$ & $0.91(0.84,0.99)$ & $3920 / 118757$ & $0.93(0.87,0.99)$ \\
\hline \multicolumn{5}{|l|}{ Income (annual) ${ }^{3}$} \\
\hline$\$ 0^{5}$ & 1586/81 524 & 1.00 ref & $3982 / 113773$ & 1.00 ref \\
\hline$\$ 80-9999$ & $679 / 57594$ & $0.83(0.75,0.91)$ & $715 / 24518$ & $0.85(0.78,0.92)$ \\
\hline$\$ 10000-19999$ & $514 / 50340$ & $0.68(0.61,0.75)$ & $300 / 12099$ & $0.76(0.67,0.85)$ \\
\hline$\$ 20000-39999$ & $713 / 57131$ & $0.75(0.68,0.82)$ & $334 / 13692$ & $0.65(0.58,0.74)$ \\
\hline$\$ \geq 40000$ & $504 / 42234$ & $0.65(0.58,0.73)$ & $281 / 11559$ & $0.59(0.51,0.67)$ \\
\hline
\end{tabular}

${ }^{1}$ Number of events (new cancers) per person-year during follow-up. ${ }^{2}$ Time-varying covariates (yearly). ${ }^{3}$ At start of follow-up. ${ }^{4}$ At end of follow-up. ${ }^{5}$ Includes also those with missing income data.

is somewhat confirmed by the lowering of the risk estimates for breast and prostate cancer once socioeconomic factors were taken into account. In contrast, for SCC survivors, the risk estimates for these three cancers rose when accounting for socioeconomic factors.

\section{Sociodemographic factors}

Several cancer diseases are strongly associated with socioeconomic resources [53] and socioeconomic factors have been suggested to represent mediators by which environmental risk factors vary within a population. In 
the present study we observed the highest cancer risk in the lowest educational and income levels, and it is likely that this may be attributed to shared adverse lifestyle factors (i.e. smoking habits, alcohol intake, sun protection, diet). The Norwegian health care system intends to ensure equal health care for all inhabitants, independent of socioeconomic level. Nevertheless, individuals who belong to a lower social class tend to have lower health vigilance and participation in surveys and screening programs to minimize the burden of cancer $[54,55]$. Therefore, we cannot exclude the possibility that our results, at least partly, might be influenced by such mechanisms.

The high risk observed in the elderly may be due to changed sun exposure habits and increased outdoor activities after retirement [56], but there may also be an effect of an age-related diminished immune response [57,58]. Analyses stratified by age, on the other hand, showed that compared to persons in the general population, the risk of a second primary cancer was greatest for the youngest skin cancer survivors, particularly for SCC survivors. A possible explanation might be a genetic susceptibility to skin cancer, which is associated with young age at diagnosis [59], and such susceptibility may also increase the risk for subsequent cancers. Further, the stronger effect of young age seen for SCC survivors may be due to the different patterns of UVR exposure associated with the two skin cancer types (intermittent/accumulated) and to behavior after diagnosis. A CMM diagnosis may, because of its lethal potential, lead to a more sunprotective behavior compared to a SCC diagnosis.

Moreover, steep increases in skin cancer rates over time has been suggested to reflect increased UVR doses [56], and this may in part explain the observed increase of subsequent cancers by calendar time.

The status of being married was associated with an increased risk of subsequent cancer after skin cancer, while having children slightly decreased the risk. Having a family influences the lifestyle in several ways, as they may help ensure more optimal medical surveillance as well as reinforce better health behaviors after diagnosis (i.e. smoking habits, alcohol intake, sun protection, diet, screening attendance) [60], which may cause these relationships.

\section{Parental cancer}

Young age at onset of the initial cancer may be an indication of a genetic predisposition [61]. Contrary to previously reported work $[21,62,63]$, having a parent with cancer did not generally increase the risk of being diagnosed with a subsequent malignancy. However, analyses restricted to individuals born after 1950, showed a near $50 \%$ increase in risk when either parent had a history of cancer. Disentangling the effect of age and parental cancer is, however, not possible due to data limitations.

\section{Time since first primary cancer}

An increased health awareness or close follow-up by the health care personnel may result in earlier diagnoses of new cancers in CMM and SCC survivors compared to that of the general cancer-free population [15,55]. Nevertheless, it is unlikely that this can fully explain the observed elevated cancer risk. Higher risk was observed in men than in women, and due to gender difference in health vigilance, we would expect the opposite as women more often interact with health care personnel [64]. The nonlinear increase for SCC survivors may help explain why the interaction terms between a skin cancer diagnosis and calendar year were statistically significant whereas the stratified analyses with a cut-point set arbitrarily in 1990 yielded overlapping confidence intervals for CMM, but not for SCC.

\section{Vitamin D}

UVR promotes vitamin $\mathrm{D}$ synthesis and vitamin $\mathrm{D}$ is demonstrated to regulate several genes involved in cancer processes and is hypothesized to inhibit cancer development [38]. Inverse relationships between a history of skin cancer, as a proxy of high vitamin D levels, and risk of subsequent cancers support this hypothesis [31,32,34-37], but the vitamin D hypothesis is not supported by the large number of studies that report increased risks of second primary cancers after skin cancer [9-30,33], and neither by the present results. We found the highest risk of subsequent cancer in the South region, which has the highest UVR dose in Norway. Recently, a study including four cohorts from different regions of Norway observed a slightly higher mean level of serum vitamin $\mathrm{D}$ in the cohort comprising residents from the southern part of the country [65]. Therefore, low levels of vitamin D might not explain our findings, although we cannot exclude the possibility that individuals with a history of skin cancer have insufficient vitamin D-levels due to changed sun-exposure habits after diagnosis. Results from a Danish study, however, counters this hypothesis as it demonstrates that previous CMM patients not are more cautious sun bathers [66]. We can also not exclude that other effects of UVR exposure, such as immunodeficiency, may play a role.

\section{Limitations and strengths}

The study has several obvious strengths including the long time-span, covering more than 50 years of followup, and the large study population, covering the entire Norwegian population. Several cancers were diagnosed in excess, but the highest risk was found for a subsequent skin cancer, particularly of similar type. General practitioners and dermatologists interacting with skin cancer survivors should be aware of this in their surveillance and follow-up. 
Individual-level information on some potential confounding variables was available and was found to influence the risk estimates. Less adjusted models are thus likely to over- or underestimate the real risk increase in skin cancer survivors, depending on the direction of the influence of excluded variables. A limitation of the study is the lack of information on parental cancer in older skin cancer survivors. Further, the use of a $20 \%$ sample resulted in larger standard errors and thus wider confidence intervals than would have been obtained if we had included the whole population. This is particularly relevant for the site-specific analyses of less common cancer forms, but nevertheless unlikely to have impacted our estimated significantly. Another limitation is the lack of behavioral risk factors such as smoking habits, sun exposure habits, body mass index (BMI), physical activity etc., which would have given more direct information on behavioral changes that may minimize the risk for a second cancer. Lastly, as we chose to primarily focus on socioeconomic factors at time of diagnosis, we are unable to account for changes in these over the life course. Such analyses would shed light on the relevance of developments in socioeconomic characteristics that have taken place in Norway as well as in other industrialized countries over the last 50 years. Nonetheless, there is litthe reason to believe that the development has been much different for skin cancer survivors compared to the general population given that we adjusted for age, calendar period and follow-up time.

\section{Conclusions}

Heightened public awareness may be important to prevent subsequent cancers in skin cancer survivors as the skin cancer incidence rates continue to rise. Of particular relevance to general practitioners and dermatologists dealing with skin cancer survivors, is the need for enhanced surveillance for a new skin cancer. Further, our results provide information on shared risk factors for first and later cancers that may help in identifying individuals at high risk for subsequent cancers, and for whom particular attention ought to be directed.

\section{Abbreviations \\ CMM: Cutaneous malignant melanoma; SCC: Squamous cell carcinoma; UVR: Ultraviolet radiation; CNS: Central nervous system; Cl: Confidence interval; OR: Odds ratio; N: Number; SIR: Standardized incidence ratio; O: Observed number of cancer cases; N/A: Not applicable; Pyr: Person-years; BMl: Body mass index $\left(\mathrm{kg} / \mathrm{m}^{2}\right)$}

\section{Competing interests}

The authors declare that they have no competing interest.

\section{Authors' contributions}

All named authors have met the criteria for authorship. All the authors made substantial contributions to conception and design and with interpretation of the results. The statistical analyses were performed by TER and AS, who also drafted the manuscript, which was critically revised by MRK and JRR. All authors ensure that the paper represent honest work and are able to verify the validity of the results reported. All authors read and approved the final manuscript.

\section{Authors' information}

TER holds a PhD in cancer epidemiology and is a senior researcher at the Cancer Registry of Norway. Her research focuses on lifestyle variables (physical activity, UVR, vitamin D) and cancer risk and survival. MRK is Professor of Community and Family Medicine in Epidemiology at Dartmouth Medical School and co-directs the Epidemiology and Chemoprevention program at Norris Cotton Cancer Center. Her research focuses on the etiology and prevention of human cancers. JRR is a physician epidemiologist who directs the New Hampshire State cancer registry and conducts research related to disease surveillance, vitamin $D$ and clinical trial methodology. AS holds a $\mathrm{PhD}$ in public health and is a senior researcher at Statistics Norway in the Research Department. Her focus is concentrated on cancer survivorship, mortality, health, and health behaviors.

\section{Funding}

This research was supported in part by a grant from the Norwegian Research Council. Drs. Karagas and Rees are supported on US NIH, National Cancer Institute grant R01 CA057494.

\section{Author details}

'Cancer Registry of Norway, PB 5313 Majorstuen, N-0304 Oslo, Norway. ${ }^{2}$ Department of Community and Family Medicine, Geisel School of Medicine, Section for Epidemiology and Biostatistics, Dartmouth Medical School, HB 7927, One Medical Center Drive, Lebanon, NH 03756, USA. ${ }^{3}$ Statisics Norway, PB 8131 Dep, 0033 Oslo, Norway.

Received: 29 May 2013 Accepted: 6 March 2014

Published: 19 March 2014

\section{References}

1. de Vries E, Coebergh JW: Cutaneous malignant melanoma in Europe. Eur J Cancer 2004, 40:2355-2366.

2. Aceituno-Madera P, Buendia-Eisman A, Arias-Santiago S, Serrano-Ortega S: Changes in the incidence of skin cancer between 1978 and 2002. Actas Dermosifiliogr 2010, 101:39-46.

3. Cancer Registry of Norway: Cancer in Norway 2011-Cancer Incidence, Mortality, Survival and Prevalence in Norway. Oslo: Cancer Registry of Norway; 2013.

4. Chang YM, Barrett JH, Bishop DT, Armstrong BK, Bataille V, Bergman W, Berwick M, Bracci PM, Elwood JM, Ernstoff MS, Gallagher RP, Green AC, Gruis NA, Holly EA, Ingvar C, Kanetsky PA, Karagas MR, Lee TK, le Marchand L, Mackie RM, Olsson H, Østerlind A, Rebbeck TR, Sasieni P, Siskind V, Swerdlow AJ, Titus-Ernstoff L, Zens MS, Newton-Bishop JA: Sun exposure and melanoma risk at different latitudes: a pooled analysis of 5700 cases and 7216 controls. Int J Epidemiol 2009, 38:814-830.

5. Leiter U, Garbe C: Epidemiology of melanoma and nonmelanoma skin cancer-the role of sunlight. Adv Exp Med Biol 2008, 624:89-103.

6. Alam M, Ratner D: Cutaneous squamous-cell carcinoma. N Engl J Med 2001, 344:975-983

7. Markovic SN, Erickson LA, Rao RD, Weenig RH, Pockaj BA, Bardia A, Vachon CM, Schild SE, McWilliams RR, Hand JL, Laman SD, Kottschade LA, Maples WJ, Pittelkow MR, Pulido JS, Cameron JD, Creagan ET: Malignant melanoma in the 21st century, part 2: staging, prognosis, and treatment. Mayo Clin Proc 2007, 82:490-513.

8. Bentham G, Aase A: Incidence of malignant melanoma of the skin in Norway, 1955-1989: associations with solar ultraviolet radiation, income and holidays abroad. Int J Epidemiol 1996, 25:1132-1138.

9. Nugent Z, Demers AA, Wiseman MC, Mihalcioiu C, Kliewer EV: Risk of second primary cancer and death following a diagnosis of nonmelanoma skin cancer. Cancer Epidemiol Biomarkers Prev 2005, 14:2584-2590.

10. Curtis RE, Freedman DM, Ron E, Ries LA, Hacker DG, Edwards BK, Tucker MA Fraumeni JF Jr: New Malignancies Among Cancer Survivors: SEER Cancer Registries, 1973-2000. Bethesda, MD: National Institute of Health; 2006. NIH Publ. 05-5302

11. Goggins W, Daniels GH, Tsao H: Elevation of thyroid cancer risk among cutaneous melanoma survivors. Int J Cancer 2006, 118:185-188. 
12. Wassberg C, Thorn M, Yuen J, Ringborg U, Hakulinen T: Second primary cancers in patients with cutaneous malignant melanoma: a populationbased study in Sweden. Br J Cancer 1996, 73:255-259.

13. Wassberg C, Thorn M, Yuen J, Ringborg U, Hakulinen T: Second primary cancers in patients with squamous cell carcinoma of the skin: a population-based study in Sweden. Int J Cancer 1999, 80:511-515.

14. Swerdlow AJ, Storm HH, Sasieni PD: Risks of second primary malignancy in patients with cutaneous and ocular melanoma in Denmark, 1943-1989. Int J Cancer 1995, 61:773-779.

15. Bradford PT, Freedman DM, Goldstein AM, Tucker MA: Increased risk of second primary cancers after a diagnosis of melanoma. Arch Dermatol 2010, 146:265-272

16. Wheless L, Black J, Alberg AJ: Nonmelanoma skin cancer and the risk of second primary cancers: a systematic review. Cancer Epidemiol Biomarkers Prev 2010, 19:1686-1695.

17. Cantwell MM, Murray L, Catney D, Donnelly D, Autier P, Boniol M, Fox C, Middleton RJ, Dolan OM, Gavin AT: Second primary cancers in patients with skin cancer: a population-based study in Northern Ireland. $\mathrm{Br} J$ Cancer 2009, 100:174-177.

18. Adami J, Frisch M, Yuen J, Glimelius B, Melbye M: Evidence of an association between non-Hodgkin's lymphoma and skin cancer. Br Med J 1995, 310:1491-1495

19. Hemminki $K$, Dong C: Subsequent cancers after in situ and invasive squamous cell carcinoma of the skin. Arch Dermatol 2000, 136:647-651.

20. Karagas MR, Greenberg ER, Mott LA, Baron JA, Ernster VL: Occurrence of other cancers among patients with prior basal cell and squamous cell skin cancer. Cancer Epidemiol Biomarkers Prev 1998, 7:157-161.

21. Rosenberg CA, Greenland P, Khandekar J, Loar A, Ascensao J, Lopez AM: Association of nonmelanoma skin cancer with second malignancy. Cancer 2004, 100:130-138.

22. Lens MB, Newton-Bishop JA: An association between cutaneous melanoma and non-Hodgkin's lymphoma: pooled analysis of published data with a review. Ann Oncol 2005, 16:460-465.

23. Maitra SK, Gallo H, Rowland-Payne C, Robinson D, Moller H: Second primary cancers in patients with squamous cell carcinoma of the skin. $\mathrm{Br} J$ Cancer 2005, 92:570-571.

24. Chen J, Ruczinski I, Jorgensen TJ, Yenokyan G, Yao Y, Alani R, Liégeois NJ Hoffman SC, Hoffman-Bolton J, Strickland PT, Helzlsouer KJ, Alberg AJ: Nonmelanoma skin cancer and risk for subsequent malignancy. J Natl Cancer Inst 2008, 100:1215-1222.

25. Spanogle JP, Clarke CA, Aroner S, Swetter SM: Risk of second primary malignancies following cutaneous melanoma diagnosis: a populationbased study. J Am Acad Dermatol 2010, 62:757-767.

26. Troyanova P, Danon S, Ivanova T: Nonmelanoma skin cancers and risk of subsequent malignancies: a cancer registry-based study in Bulgaria. Neoplasma 2002, 49:81-85.

27. Balamurugan A, Rees JR, Kosary C, Rim SH, Li J, Stewart SL: Subsequent primary cancers among men and women with in situ and invasive melanoma of the skin. J Am Acad Dermatol 2011, 65(Suppl 1):69-77.

28. Frisch $M$, Melbye $M$ : New primary cancers after squamous cell skin cancer. Am J Epidemiol 1995, 141:916-922.

29. Levi F, randimbison L, La Vecchia $C$, Erler G, Te V-C: Incidence of invasive cancers following squamous cell skin cancer. Am J Epidemiol 1997, 146:734-739.

30. Song F, Quresti AA, Giovannucci EL, Fuchs CS, Chen WY, Stampfer MJ, Han $\mathrm{J}$ : Risk of a second primary cancer after non-melanoma skin cancer in white men and women: a prospective cohort study. PLoS Med 2013, 10:e1001433.

31. Tuohimaa P, Pukkala E, Scelo G, Olsen JH, Brewster DH, Hemminki K, Tracey E, Weiderpass E, Kliewer EV, Pompe-Kirn V, McBride ML, Martos C, Chia KS, Tonita JM, Jonasson JG, Boffetta P, Brennan P: Does solar exposure, as indicated by the non-melanoma skin cancers, protect from solid cancers: vitamin D as a possible explanation. Eur J Cancer 2007, 43:1701-1712.

32. de Vries E, Soerjomataram I, Houterman S, Louwman MW, Coebergh JW: Decreased risk of prostate cancer after skin cancer diagnosis: a protective role of ultraviolet radiation? Am J Epidemiol 2007, 165:966-972.

33. Levi F, Randimbison L, Te VC, Conconi MM, La VC: Risk of prostate, breast and colorectal cancer after skin cancer diagnosis. Int J Cancer 2008, 123:2899-2901.

34. Soerjomataram I, Louwman WJ, Lemmens VE, Coebergh JW, de Vries E: Are patients with skin cancer at lower risk of developing colorectal or breast cancer? Am J Epidemiol 2008, 167:1421-1429.
35. Grant WB: A meta-analysis of second cancers after a diagnosis of nonmelanoma skin cancer: additional evidence that solar ultraviolet-B irradiance reduces the risk of internal cancers. J Steroid Biochem Mol Biol 2007, 103:668-674.

36. Hughes AM, Armstrong BK, Vajdic CM, Turner J, Grulich AE, Fritschi L, Milliken S, Kaldor J, Benke G, Kricker A: Sun exposure may protect against non-Hodgkin lymphoma: a case-control study. Int J Cancer 2004, 112:865-871.

37. Giovannucci $E$ : The epidemiology of vitamin $D$ and cancer incidence and mortality: A review (United States). Cancer Causes Control 2005, 16:83-95.

38. Garland CF, Garland FC: Do sunlight and vitamin D reduce the likelihood of colon cancer? Int J Epidemiol 1980, 9:227-231.

39. Larsen IK, Smastuen M, Johannesen TB, Langmark F, Parkin DM, Bray F, Møller B: Data quality at the cancer registry of Norway: an overview of comparability, completeness, validity and timeliness. Eur J Cancer 2009, 45:1218-1231

40. Robsahm TE, Tretli S: Cutaneous malignant melanoma in Norway: variation by region of residence before and after the age 17. Cancer Causes Control 2001, 12:569-576.

41. StataCorp: Stata Statistical Software: Release 12. College Station, TX StataCorp LP; 2011

42. Allison PD: Survival Analysis Using SAS. A Practical Guide. Cary, NC: SAS Institute Inc; 1995

43. Lens MB, Dawes M: Global perspectives of contemporary epidemiological trends of cutaneous malignant melanoma. Br J Dermatol 2004, 150:179-185.

44. McKenna DB, Doherty VR, McLaren KM, Hunter JA: Malignant melanoma and lymphoproliferative malignancy: is there a shared aetiology? $\mathrm{Br} J$ Dermatol 2000, 143:171-173.

45. McMichael AJ, Giles GG: Have increases in solar ultraviolet exposure contributed to the rise in incidence of non-Hodgkin's lymphoma? $\mathrm{Br}$ Cancer 1996, 73:945-950

46. Boldeman C, Brandt L, Berg L, Ekbom A, Hall P: Risk of non-Hodgkin's lymphoma and skin malignancies in patients diagnosed with cataract. Eur J Cancer Prev 2004, 13:281-285.

47. Hemminki K, Jiang Y, Steineck G: Skin cancer and non-Hodgkin's lymphoma as second malignancies. markers of impaired immune function? Eur $J$ Cancer 2003, 39:223-229.

48. Werkmeister J, Phillips G, McCarthy W, Hersey P: Suppressor cell activity in melanoma patients. II. Concanavalin A-induced suppressor cells in relation to tumor growth and suppressor T-cell subsets. Int J Cancer 1981, 28:11-15.

49. Vanhaelen CP, Fisher RI: Increased sensitivity of T cells to regulation by normal suppressor cells persists in long-term survivors with Hodgkin's disease. Am J Med 1982, 72:385-390.

50. Travis LB, Curtis RE, Glimelius B, Holowaty E, van Leeuwen FE, Lynch CF, Adami J, Gospodarowicz M, Wacholder S, Inskip P, Tucker MA, Fraumeni JF $J r$, Boice JD Jr: Second cancers among long-term survivors of nonHodgkin's lymphoma. J Natl Cancer Inst 1993, 85:1932-1937.

51. Grodstein F, Speizer FE, Hunter DJ: A prospective study of incident squamous cell carcinoma of the skin in the nurses' health study. J Natl Cancer Inst 1995, 87:1061-1066.

52. Goggins W, Gao W, Tsao H: Association between female breast cancer and cutaneous melanoma. Int J Cancer 2004, 111:792-794.

53. Faggiano F, Partanen T, Kogevinas M, Boffetta P: Socioeconomic differences in cancer incidence and mortality. Lyon: IARC Sci Publ 1997, 138:65-176.

54. Kravdal Ø: Social inequalities in cancer survival. Tidskr Nor Lægeforen 1999, 119:1577-1583.

55. Hiatt RA, Krieger N, Sagebiel RW, Clark WH Jr, Mihm MC Jr: Surveillance bias and the excess risk of malignant melanoma among employees of the Lawrence Livermore National Laboratory. Epidemiology 1993, 4:43-47.

56. Robsahm TE, Bergva G, Hestvik UE, Møller B: Sex differences in rising trends of cutaneous malignant melanoma in Norway, 1954-2008. Melanoma Res 2013, 23:70-78.

57. Lehtonen L, Eskola J, Vainio O, Lehtonen A: Changes in lymphocyte subsets and immune competence in very advanced age. J Gerontol 1990, 45:108-112.

58. Thivolet J, Nicolas JF: Skin ageing and immune competence. $\mathrm{Br} J$ Dermatol 1990, 122(Suppl 35):77-81.

59. Nasser N, UVB: Susceptibility in malignant melanoma. An Bras Dermatol 2010, 85:843-848. 
60. Kravdal Ø: Children, family and cancer survival in Norway. Int $J$ Cancer 2003, 105:261-266.

61. Goldstein AM, Landi MT, Tsang S, Fraser MC, Munroe DJ, Tucker M: Association of MC1R variants and risk of melanoma in melanoma-prone families with CDKN2A mutations. Cancer Epidemiol Biomarkers Prev 2005, $14: 2208-2212$

62. Zhang $\mathrm{H}$, Bermejo $\mathrm{JL}$, Sundquist J, Hemminki K: Modification of second cancer risk after mailignant melanoma by parental history of cancer. $\mathrm{Br} J$ Cancer 2008, 99:536-538.

63. Siskind V, Hughes MC, Palmer JM, Symmons JM, Aitken JF, Martin NG, Hayward NK, Whiteman DC: Nevi, family history, and fair skin increase the risk of second primary melanoma. J Invest Dermatol 2011, 131:461-467.

64. Cambell SM, Roland MO: Why do people consult the doctor? Fam Pract 1996, 13:75-83.

65. Holvik K, Ahmed LA, Forsmo S, Gjesdal CG, Grimnes G, Samuelsen SO, Schei B, Blomhoff R, Tell GS, Meyer HE: Low serum levels of 25-hydroxyvitamin D predict Hip fracture in the elderly: a NOREPOS study. J Clin Endocrinol Metab 2013, 98:3341-3350.

66. Idorn LW, Datta P, Heydenreich J, Philipsen PA, Wulf HC: A 3-year follow-up of Sun behavior in patients with cutaneous malignant melanoma. JAMA Dermatol 2013 [Epub ahead of print].

doi:10.1186/1471-2407-14-210

Cite this article as: Robsahm et al.: New malignancies after squamous cell carcinoma and melanomas: a population-based study from Norway. BMC Cancer 2014 14:210.

\section{Submit your next manuscript to BioMed Central and take full advantage of:}

- Convenient online submission

- Thorough peer review

- No space constraints or color figure charges

- Immediate publication on acceptance

- Inclusion in PubMed, CAS, Scopus and Google Scholar

- Research which is freely available for redistribution 